\title{
Hyperalaninaemia is an early feature of diabetes secondary to total pancreatectomy
}

\author{
S. Del Prato, S. Vigili de Kreutzenberg, R. Trevisan, E. Duner, A. Avogaro, R. Nosadini, U. Baccaglini, C. Tremolada \\ and A. Tiengo \\ Cattedra di Malattie del Ricambio e Patologia Medica, and Clinica Chirurgica I, University of Padova, Italy
}

\begin{abstract}
Summary. High levels of gluconeogenic precursors have been reported in patients with long-term diabetes secondary to total pancreatectomy. In the present study, blood concentrations of alanine, lactate and pyruvate were measured in six patients undergoing total pancreatectomy and in nine control subjects undergoing major abdominal surgery. To exclude the simple effect of lack of insulin and hyperglycaemia in the development of hyperalaninaemia following total pancreatectomy, three pancreatectomized patients and five control subjects underwent surgical operation while connected to an artificial pancreas. Blood concentration of alanine was constant in the control subjects during surgery $(182 \pm 20$ and $243 \pm 31 \mu \mathrm{mol} / \mathrm{I}$ with and without the artificial pancreas, respectively). In pancreatectomized patients basal blood alanine levels were simi-
\end{abstract}

lar to those in control subjects. Blood alanine level rose quickly after removal of the pancreas from $182 \pm 24$ to $285 \pm 15$ $\mu \mathrm{mol} / 1(p<0.05)$ in the patients connected to the artificial pancreas, and from $198 \pm 17$ to $395 \pm 47 \mu \mathrm{mol} / 1(p<0.05)$ in patients undergoing total pancreatectomy without artificial pancreas. These values were higher than those observed in the control subjects at the end of the operation $(192 \pm 22$ and $230 \pm 45 \mu \mathrm{mol} / 1$ with and without artificial pancreas, respectively.) Basal and intraoperative blood concentrations of lactate and pyruvate were similar in pancreatectomized patients and control subjects.

Key words: pancreatogenic diabetes, pancreatectomy, glucagon, alanine, lactate, pyruvate.
Diabetes secondary to total pancreatectomy demonstrates specific metabolic features [1-6]. In particular, high blood concentrations of lactate, pyruvate, and alanine are found in patients who have diabetes after total pancreatectomy [2-6]. Furthermore, in these patients elevated blood levels of several amino acids are found $[4,7,8]$. Alanine and gluconeogenic amino acids are increased, while no significant variation is observed for the branched-chain amino acids $[4,7,8]$. It has been proposed that these metabolic abnormalities may result from a reduced gluconeogenesis rate secondary to chronic glucagon deficiency $[3,4,6-8]$. This is supported by the observation that physiological replacement of the basal glucagon level leads to a significant decline in these metabolites and a fall in gluconeogenic amino acids [8, 9]. However, all these studies were performed in patients after long-standing pancreatectomy and little is known about the time course in the development of these metabolic changes.

The present study was designed to evaluate the relationship between glucagon disappearance from the circulation and the changes in blood alanine, lactate, and pyruvate in patients undergoing total pancreatectomy for pancreatic neoplasia.

\section{Subjects and methods}

\section{Subjects}

Six patients (four males, two females) undergoing total pancreatectomy for pancreatic adenocarcinoma were studied. The patient's age ranged from 40 to 70 years and body mass index from 20 to $23 \mathrm{~kg} / \mathrm{m}^{2}$. Nine patients with neoplasia (eight males, one female) undergoing major abdominal surgery were studied as controls. These patients were aged $43-73$ years and their mean body mass index ranged from 20 to $24 \mathrm{~kg} / \mathrm{m}^{2}$. All subjects gave their informed consent to the study. None had a family history of diabetes. Before surgery, the mean fasting blood glucose concentration was $6.2 \pm 0.3 \mathrm{mmol} / 1$ in the patients undergoing total pancreatectomy and $5.9 \pm 0.5 \mathrm{mmol} / 1$ in the control subjects. Each patient received partial parenteral nutrition (glucose $75 \mathrm{~g} /$ day) for the 3 days preceding operation. The glucose infusion was stopped $1 \mathrm{~h}$ before the beginning of the surgical procedure, and a saline infusion $(0.154 \mathrm{~mol} / \mathrm{l})$ was maintained thereafter. The same anaesthetic procedure was used in all subjects. Anaesthesia (NLA2 technique) was induced with thiopental sodium $(15 \mathrm{mg} / \mathrm{kg})$ and dehydrobenzoperidol $(0.15 \mathrm{mg} / \mathrm{kg})$. Thereafter, it was maintained with fentanyl citrate $(25 \mu \mathrm{gg} / \mathrm{kg})$. Mioresolution was obtained with pancuronium bromide $(0.25 \mathrm{mg} / \mathrm{kg})$. No patient required blood transfusion during the surgical operation.

To avoid the possible effect of insulin deficiency and hyperglycaemia, three pancreatectomy patients and five control subjects were connected to an artificial endocrine pancreas (Biostator, Life Instruments, Ulm, FGR) $60 \mathrm{~min}$ before the beginning of surgery. The remaining patients underwent surgery without insulin infusion. 


\section{Methods}

In the patients connected to the artificial endocrine pancreas, basal glucose concentrations were maintained throughout the operation by means of an automatic insulin infusion. The rate of insulin infusion was calculated at 1-min intervals by the artificial endocrine pancreas, according to the control algorithm. The operating constants were: for rising glucose levels $(K R)=165$, for falling glucose levels $(K F)=45$;
Without ortificial pancreos

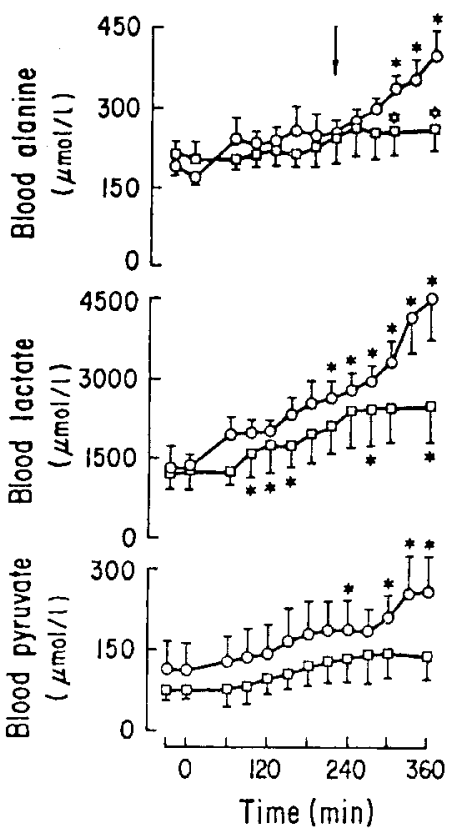

With artificial poncreos
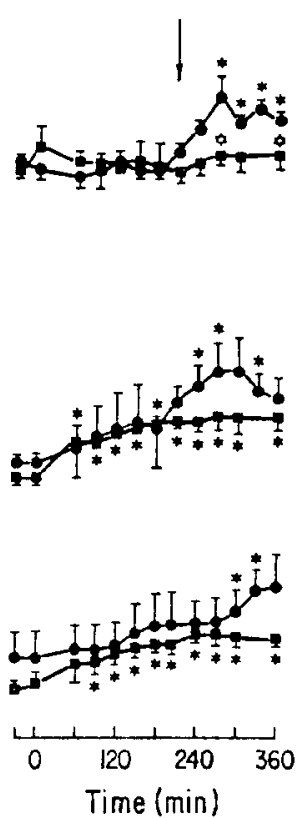

Fig. 1. Blood concentrations of alanine, lactate and pyruvate (mean \pm SEM) in patients undergoing total pancreatectomy with $(\bullet)$ or without $(O)$ artificial pancreas, and in control patients undergoing major abdominal surgery (with artificial pancreas $=\mathbf{\square}$; without artificial pancreas $=\square$ ). Arrow indicates the mean time of functional isolation of the pancreas. ${ }^{*} p<0.05$ compared with basal values; is $p<0.05$ between pancreatectomy and control groups the inverse of the static gain for insulin infusion $(\mathrm{QI})=30$, the basal level at which the basal insulin infusion rate $(\mathrm{RI}=15 \mathrm{mU} / \mathrm{min})$ was administered was $4.5 \mathrm{mmol} / \mathrm{l}(\mathrm{BI})$. A radial artery was cannulated with a teflon catheter (Angiocath, The Desert Company, Sandy, Utah, USA) for blood pressure monitoring and blood sample collection. After two basal samples, blood $(7-8 \mathrm{ml})$ was drawn from the arterial cannula at $30-\mathrm{min}$ intervals for $360 \mathrm{~min}$ from the beginning of the surgical procedure (skin incision). An aliquot $(5 \mathrm{ml})$ of blood was collected in tubes containing $1.2 \mathrm{mg}$ EDTA and aprotinine $500 \mathrm{U} / \mathrm{ml}$ (Trasylol, Bayer, Leverkusen, FGR) for the determination of insulin [10], Cpeptide [11] and total glucagon immunoreactivity (using $30 \mathrm{~K}$ antiserum) [12]. A second aliquot (1.5 ml) of blood was collected in tubes containing $5 \mathrm{ml}$ of $5 \%$ percloric acid for deproteinization. After centrifugation at $600 \mathrm{~g}$ for $15 \mathrm{~min}$, the surnatant was taken up for the fluoroenzymatic assay of glucose, alanine, pyruvate, and lactate [13].

\section{Statistical analysis}

All values are expressed as mean \pm SEM. Statistical significance was determined by the Studient's t-test and the analysis of variance for repeated measurements [14].

\section{Results}

\section{Without artificial pancreas control}

The plasma levels of insulin, C-peptide, total glucagon immunoreactivity and blood concentrations of glucose alanine, lactate and pyruvate were comparable in patients undergoing total pancreatectomy and major abdominal surgery (control subjects) at the beginning of the surgical procedure (Table 1, Fig.1). During surgery blood glucose levels rose progressively in both groups (Table 1). However, at the end of the operation, the blood glucose levels were higher in the pancreatectomy patients than in the control subjects $(15.1 \pm 0.9$ versus, $9.0 \pm 0.5 \mathrm{mmol} / 1, p<0.05)$. In the pancreatectomy pat-

Table 1. Blood and plasma metabolites and hormone concentrations in patients undergoing total pancreatectomy or major abdominal surgery (control subjects) with and without an artificial pancreas

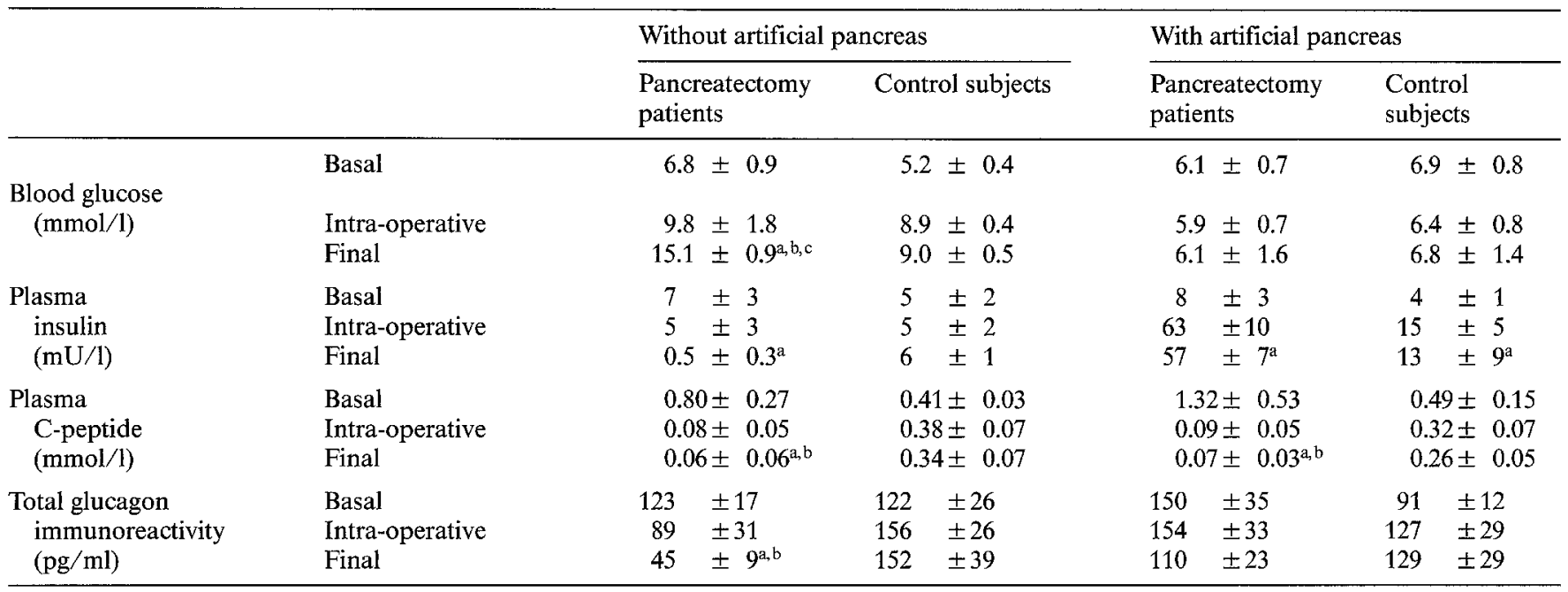

The basal value represents the average of two samples drawn 30 and $15 \mathrm{~min}$ before the beginning of surgical procedure. The intraoperative value represents the average of 10-12 samples collected at 30-min intervals during the surgical procedure. The final value represents the samples drawn 360 min after the beginning of the operation. Results are expressed as mean $\pm \mathrm{SEM}$.

${ }^{\mathrm{a}} p<0.05$ final versus basal values; ${ }^{\mathrm{b}} p<0.05$ between pancreatectomy patients and control subjects; ${ }^{\mathrm{c}} p<0.05$ between with and without artificial pancreas groups 
ients, plasma concentration of insulin and C-peptide decreased significantly during the surgical operation, so that at the end of the operation the hormone concentrations were significantly lower than in the control subjects $(0.5 \pm 0.3$ versus $6.0 \pm 1.0 \mathrm{mmol} / 1 ; p<0.05$; Table 1). Plasma total glucagon immunoreactivity slightly increased in the control subjects, while it decreased progressively in the pancreatectomy patients (Table 1). In the control subjects, blood alanine concentrations did not change significantly (Fig. 1). In pancreatectomy patients, blood alanine remained constant until the time of the removal of the pancreas. After that, blood alanine increased from $182 \pm 24$ to $285 \pm$ $15 \mu \mathrm{mol} / 1$ at the end of the operation $(\mathrm{F}=8.915, p<$ $0.01)$.

Basal blood concentrations of lactate and pyruvate were similar in both groups. During the operation, however, both blood lactate and pyruvate levels increased progressively (Fig. 1). At the end of operation, blood lactate concentrations were higher, but not significantly different, in the pancreatectomy patients $(4450 \pm$ 807 versus $2081 \pm 368 \mu \mathrm{m} / \mathrm{l}$ ). No differences were found in blood pyruvate concentrations $(222 \pm 82$ and $152 \pm 24 \mu \mathrm{mol} / 1)$.

\section{With artificial pancreas control}

Basal levels of plasma insulin, C-peptide, total glucagon immunoreactivity and blood concentration of glucose, alanine, lactate and pyruvate were comparable in patients undergoing total pancreatectomy or major abdominal surgery (Table 1). They were also similar to those observed in the patients undergoing surgery without artificial pancreas (Table 1). The basal blood glucose concentration was kept constant throughout surgical procedure and was comparable in pancreatectomy and control groups. The maintainance of constant normoglycaemia required higher concentration of plasma insulin in pancreatectomy patients than in control subjects $(57 \pm 7$ versus $13 \pm 9 \mathrm{mU} / 1 ; p<0.05)$. As observed in the patients undergoing surgery without artificial pancreas, the effective removal of the pancreas was documented by the reduction of plasma C-peptide concentration towards the lower limit of detection by the radioimmunoassay $(0.07 \pm 0.03 \mathrm{mmol} / \mathrm{l})$. Although in the control subjects plasma C-peptide levels declined slightly during surgery, they remained significantly higher than in the pancreatectomy patients at the end of the operation $(0.26 \pm 0.05$ versus $0.07 \pm 0.03 \mathrm{mmol} / 1 ; p<0.05)$. Plasma total glucagon immunoreactivity progressively decreased in pancreatectomy patients, while a slight increase was observed in control subjects (Table 1). Blood concentration of alanine, lactate, and pyruvate displayed the same trend observed in the patients undergoing surgery without artificial pancreas (Fig.1). Blood concentration of alanine remained constant in control subjects throughout the surgical operation. In contrast, in pancreatectomy patients alanine promptly began to rise after the removal of the pancreas (from $198 \pm 17$ to $395 \pm 47 \mu \mathrm{mol} / 1 ; p<0.05)$. Basal blood concentrations of lactate and pyruvate were similar in pancreatectomy patients $(1104 \pm 129$ and $108 \pm 21 \mu \mathrm{mol} / \mathrm{l})$ and control patients $(1218 \pm 108$ and $68 \pm 14 \mu \mathrm{mol} / 1)$. During the surgery procedure both blood lactate and pyruvate levels increased progressively (Fig.1). Blood concentrations of lactate and pyruvate at the end of the operation were not significantly different between control and pancreatectomy patients (2081 \pm 241 versus $2494 \pm$ $482 \mu \mathrm{mol} / 1$ and $144 \pm 17$ versus $167 \pm 18 \mu \mathrm{mol} / 1$, respectively). There was no significant difference between the pancreatectomy patients receiving insulin and those not connected to the artificial pancreas. When data were analyzed by analysis of variance for repeated measurements, a significant time effect on blood alanine concentration was observed $(\mathrm{F}=21.668 ; p<0.001)$.

\section{Discussion}

This study confirms previous observations that hyperalaninaemia is a constant finding in diabetes secondary to total pancreatectomy, and clearly demonstrates that the rise in blood alanine concentration develops rapidly after removal of the pancreas. Hyperalaninaemia has been observed in pancreatectomized animals $[15,16]$ and man [2-9] and glucagon deficiency has been suggested as a cause for this metabolic abnormality [2-9]. However, in dogs, pancreatectomy does not lead to glucagon deficiency because of a compensatory increase in the secretion of extrapancreatic glucagon. This extrapancreatic glucagon is biologically undistinguishable from the pancreatic glucagon [17-19]. Man after total pancreatectomy is the only known mammal with glucagon deficiency $[1-9,20]$. Nonetheless, in individuals after pancreatectomy, other factors such as nutrition, malabsorption, changes in dietary behaviour, abnormalities in gastrointestinal hormone secretion, local recurrence and/or metastatic malignancy, could affect intermediary metabolism and alter blood amino acid profiles. These factors are unlikely explanations in the present study, since the increase in blood alanine concentration was immediately after the removal of the pancreas, suggesting a direct relationship with a pancreatic hormone. Other factors intrinsic to the surgical procedure, such as hyperglycaemia, cannot account for the rise in blood alanine levels. Firstly, the alanine concentration remained unchanged in the control subjects, while in pancreatectomy patients it rose only after the removal of the pancreas. Secondly, the same time-related increase in alanine concentration was observed when blood glucose was kept constant with an artificial pancreas. In patients undergoing total pancreatectomy, the blood alanine level increased both in the presence and absence of circulating insulin concentrations. This finding is in agreement with our previous observations that intensive insulin therapy does not reduce blood al- 
anine levels in patients with diabetes secondary to pancreatectomy [6]. We interpret our results as indicating a direct relationship between the disappearance of glucagon from the circulation following total pancreatectomy and the concomitant rise in blood alanine level. Even though total glucagon immunoreactivity did not become undetectable after pancreatectomy, total pancreatic glucagon deficiency can be assumed by the end of the surgical operation. In fact, the completeness of pancreatectomy was confirmed by the decline in plasma C-peptide concentration. To assess further the completeness of pancreatic glucagon deficiency, we chromatographed plasma samples obtained from the portal vein of one subject before and $15 \mathrm{~min}$ after an arginine challenge. Following pancreatectomy we detected neglectable amounts of pancreatic glucagon (data not shown). Therefore, the measurable glucagon immunoreactivity in these patients represents the non-specificity of the $30 \mathrm{~K}$ antibody which cross-reacts with extrapancreatic glucagonlike material [20-23]. Since the half life $(\mathrm{t} 1 / 2)$ of glucagon has been estimated to be less than $10 \mathrm{~min}$ [24], we can assume that $30 \mathrm{~min}$ after removal of the pancreas all patients were virtually aglucagonaemic. With respect to this, it is noteworthy that blood alanine concentrations began to increase 30-60 min after pancreatectomy, and this rise reached statistical significance at $120-150 \mathrm{~min}$. Unfortunately, any conclusion concerning the mechanism(s) underlying the elevation in plasma alanine concentration following acute glucagon deficiency cannot be drawn without the use of radioisotopic kinetic analysis. However, we believe that the most likely explanation underlying the rise in blood alanine concentration following pancreatectomy is reduced liver uptake and a diminished rate of gluconeogenesis. It is now generally accepted that physiological changes in plasma glucagon levels have no direct effect on muscle alanine release [25]. On the other hand, a primary role of glucagon in the regulation of hepatic gluconeogenesis [26] and alanine uptake [27] has been well documented [28]. Our observation are consistent with data published by Boden et al. [29]. These investigators demonstrated that glucagon deficiency, induced in normal subjects by somatostatin infusion, lead to a $23 \%$ decrease in plasma alanine concentration. In contrast, Müller et al. [8] replaced physiological glucagon concentration in six patients with total pancreatectomy and demonstrated normalization of alanine levels and other aminoacids. Using similar doses of glucagon in pancreatectomy patients, we were able to demonstrate a similar effect on blood alanine concentration in association with an increase in the rate of glucose recycling [9]. Our data are also in agreement with those reported by Cherrington et al. in dogs [30]. In these animals, the somatostatin suppression of insulin and glucagon was followed by a marked enhancement in alanine levels, as a consequence of a diminished disappearance rate of the amino acid from plasma. In contrast, alanine conversion to glucose was significantly higher when basal portal glucagon levels were replaced than during combined glucagon and insulin suppression. Previous studies have also demonstrated high concentrations of lactate and pyruvate in patients with complete pancreatectomy $[2,3,6]$. It is likely that the elevated concentrations of these metabolites are also due to diminished gluconeogenesis. However, under the present experimental conditions we did not observe any difference in lactate and pyruvate between pancreatectomy patients and control subjects during surgical operation. In both groups the concentrations of the two metabolites increased continuously from the beginning to the end of surgery. High concentrations of lactate and pyruvate have previously been reported after major operations [31]. This is the result of increased extrahepatic production, probably related to an increase concentration of catecholamines [32] and some inhibition of pyruvate oxidation [33]. Glucagon directly stimulates gluconeogenesis by increasing alanine transport across the hepatocyte membrane; in contrast, there is no evidence that the hepatic uptake of lactate and pyruvate is under direct glucagon control [28]. Thus, both increased peripheral production of lactate and pyruvate due to surgical stress, and the absence of a direct glucagon action on liver uptake of the two metabolites can account for the absence of differences between pancreatectomy patients and control subjects. In conclusion, our results indicate that hyperalaninaemia rapidly develops after glucagon deficiency and point out that this metabolic abnormality is a characteristic feature of diabetes secondary to total pancreatectomy.

Acknowledgements. The authors express their gratitude to C. Foote for her patience and skill in typing this manuscript. This study was supported by the National Council for Research (CNR grant 83.02857.56; 84.02551.56 Roma Progetto Finalizzato Medicina Preventiva.

\section{References}

1. Del Prato S, Nosadini R, Riva F, Fedele D, Devide A, Tiengo A (1980) Glucagon levels and ketogenesis in human diabetes following partial or total pancreatectomy and severe chronic pancreatitis. Acta Diabetol Lat 17: 111-118

2. Barnes AJ, Bloom SR, Alberti KGMM, Smith PP, Alford FP, Chisolm DJ (1977) Ketoacidosis in pancreatectomized man. N Engl J Med 296: 1250-1253

3. Barnes AJ, Bloom SR, Alberti KGMM, Smythe P, Turnell D (1977) Persistent metabolic abnormalities in diabetes in the absence of glucagon. Diabetologia 13: 71-75

4. Boden G, Master RW, Rezvani I, Palmer JP, Lobe TE, Owen OE (1980) Glucagon deficiency and hyperaminoacidemia after total pancreatectomy. J Clin Invest 65: 706-716

5. Nosadini R, Del Prato S, Tiengo A, Duner E, Toffolo G, Cobelli C, Faronato PP, Moghetti P, Muggeo M (1982) Insulin sensitivity, binding, and kinetics in pancreatogenic and type I diabetes. Diabetes $31: 346-355$

6. Del Prato S, Tiengo A, Baccaglini U, Tremolada C, Duner E, Marescotti MC, Avogaro A, Valverde I, Nosadini R, Assan R (1983) Effect of insulin replacement in intermediary metabolism in diabetes secondary to pancreatectomy. Diabetologia 25: 252-259 
7. Müller WA, Berger M, Suter P, Currers HJ, Reiter J, Wyss T, Berchtold D, Schmidt FH, Assal JP, Renold AE (1979) Glucagon immunoreactivity and aminoacid profile in plasma of duodenopancreatectomized patients. J Clin Invest 63: 820-827

8. Müller WA, Cuppers HJ, Zimmerman-Telshow H, Micheli H, Wyss T, Renold AE, Berger M (1983) Aminoacids and lipoproteins in plasma of duodenopancreatectomized patients: effects of glucagon in physiological amounts. Eur J Clin Invest 13: 141-149

9. Del Prato S, Vigili de Kreutzenberg S, Trevisan R, Duner E, Valerio A, Baccaglini U, Tremolada C, Tiengo A (1983) Normalization of intermediary metabolites by insulin and glucagon replacement in pancreatectomized diabetic patients. Diabetologia 25:150 (Abstract)

10. Jorgensen KR (1969) Radioimmunoassay of insulin in plasma and urine of obese subjects and in diabetic patients. Acta Endocrinol 60:719-725

11. Kuzuya T, Matsuda TS, Yoshida S (1976) Human C-peptide immunoreactivity in blood and urine: evaluation of a radioimmunoassay method and its clinical applications. Diabetologia 12 : 511-518

12. Faloona GR, Unger RH (1974) Glucagon. In: Yaffe BM, Behrman HR (eds) Methods of hormone radioimmunoassay. Academic press, New York, pp 317-323

13. Lloyd B, Burrin J, Smythe P, Alberti KGMM (1978) Enzymic fluorimetric continuous flow assays for blood glucose, lactate, pyruvate, alanine, glycerol and 3-hydroxybutirate. Clin Chem 24: 1724-1729

14. Snedecor GW, Cochran WG (1967) Statistical methods. 6th edn. Iowa State University Press, Ames, Iowa

15. Albisser AM, Zinman B, Marliss EB, Botz CK (1980) The metabolic and hormonal responses to glucose infusion in anaesthetized normal and diabetic dogs controlled by an artificial B-cell. Diabetologia 18: 479-485

16. Goriya Y, Bahoric A, Marliss EB, Zinman B, Albisser AM (1981) The metabolic and hormonal responses to a mixed meals in unrestrained pancreatectomized dogs chronically treated by portal or peripheral insulin infusion. Diabetologia 21: 56-64

17. Matsuyama T, Foa PP (1974) Plasma glucose, insulin, pancreatic and enteroglucagon levels in normal and depancreatized dogs. Proc Soc Exp Biol Med 147: 97-102

18. Vranic M, Pek S, Kawamori R (1974) Increased glucagon immunoreactivity in plasma of totally depancreatized dogs. Diabetes 23:613-616

19. Mashiter K, Harding PE, Chou M, Mashiter GD, Stout J, Diamond D, Field JB (1975) Persistent pancreatic glucagon but not insulin response to arginine in pancreatectomized dogs. Endocrinology $96: 678-683$

20. Tiengo A, Bessioud M, Valverde I, Tabbi-Anneni A, Del Prato S, Alexandre J, Assan R (1982) Absence of islet alpha-cell function in pancreatectomized patients. Diabetologia $22: 25-32$
21. Valverde I, Villanueva ML, Lozano L, Marco J (1974) Presence of glucagon immunoreactivity in the globulin fraction of human plasma (big plasma glucagon). J Clin Endocrinol Metab 39: 1090-1098

22. Valverde I, Dobbs R, Unger RH (1975) Heterogeneity of plasmaglucagon immunoreactivity in normal, depancreatized, and alloxan diabetic dogs. Metabolism 24: 1021-1028

23. Villanueva ML, Hedo JA, Marco J (1976) Plasma glucagon immunoreactivity in a total pancreatectomized patient. Diabetologia 12: 613-616

24. Alford FP, Bloom SR, Nabarro JDN (1976) Glucagon metabolism in man. Studies on the metabolic clearance rate and the plasma acute disappearance time of glucagon in normal and diabetic subjects. J Clin Endocrinol Metab 42: 830-838

25. Pozefsky T, Tancredi RG, Maxly RT, Dupre J, Tobin J (1976) Metabolism of forearm tissues in man. Studies with glucagon. Diabetes 25: 128-135

26. Jennings AS, Cherrington AD, Liljenquist JE, Keller U, Lacy WW, Chiasson JL (1976) The roles of insulin and glucagon in the regulation of gluconeogenesis in the post-absorptive dog. Diabetes $26: 847-856$

27. Rabin D, Mueller GL, Lacy WW, Liljenquist JE (1979) Splanchnic metabolism of alanine in intact man: effects of somatostatin and somatostatin plus insulin. Diabetes 28: 486-490

28. Cherrington AD (1981) Gluconeogenesis: its regulation by insulin and glucagon. In: Brownlee (ed) Diabetes mellitus, Vol 3, Sarlend SPIM Press, New York, pp 49-117

29. Boden G, Rezvani I, Owen OE (1984) Effects of glucagon on plasma amino acids. J Clin Invest 73: 785-793

30. Cherrington AD, Lacy WW, Chiasson JL (1978) Effects of glucagon on glucose production during insulin deficiency in the dog. $\mathbf{J}$ Clin Invest 57: 664-677

31. Schweizer SS, Howland WS (1965) Significance of lactate and pyruvate according to volume of blood transfusion in man. Ann Surg 162: 1017-1027

32. Halter JB, Pflug AE, Porte D Jr (1965) Mechanism of plasma catecholamine increase during surgical stress in man. J Clin Endocrinol Metab 45: 936-944

33. Ryan TR (1976) Metabolic adaptation for energy production during trauma and sepsis. Surg Clin N Am 56: 1073-1090

Received: 20 January 1984

and in revised form. 18 March 1985

Dr. Stefano Del Prato

Cattedra di Malattie del Ricambio

Universita di Padova

Via Giustiniani, 2

I-35100 Padova

Italy 